82

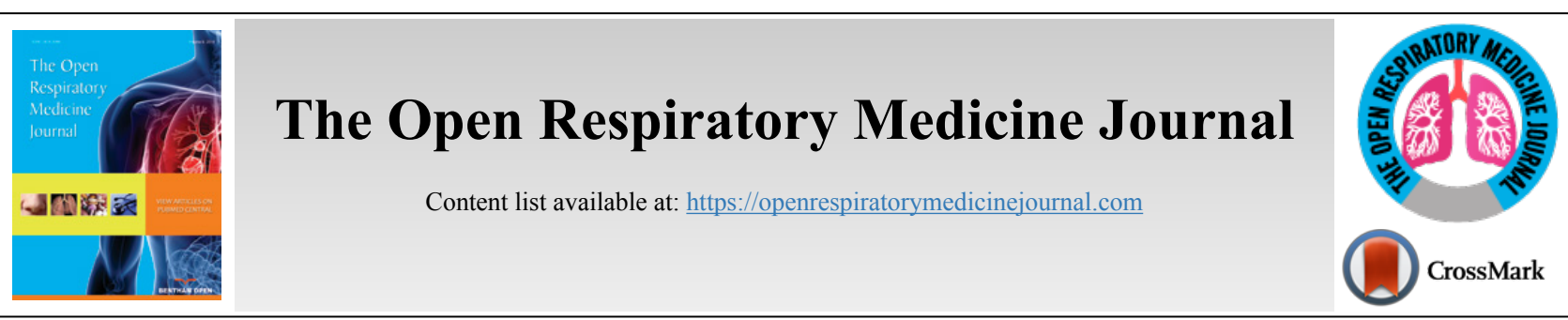

REVIEW ARTICLE

\title{
Diaphragm Ultrasound in the Evaluation of Diaphragmatic Dysfunction in Lung Disease
}

\author{
Sebastián Lux ${ }^{1,2, *}$, Daniel Ramos ${ }^{1,3,4}$, Andrés Pinto ${ }^{1,4}$, Sara Schilling ${ }^{4}$ and Mauricio Salinas ${ }^{3,4}$ \\ ${ }^{1}$ Resident, Pulmonary Medicine, Universidad de Chile, Instituto Nacional del Tórax, Santiago, Chile \\ ${ }^{2}$ Unidad de Paciente Crítico, Hospital Barros Luco Trudeau, Santiago, Chile \\ ${ }^{3}$ Unidad de Paciente Crítico, Clínica Santa María, Santiago, Chile \\ ${ }^{4}$ Facultad de Medicina, Universidad de Chile, Santiago, Chile
}

\begin{abstract}
:
The diaphragm is the most important respiratory muscle, and its function may be limited by acute and chronic diseases. A diaphragmatic ultrasound, which quantifies dysfunction through different approaches, is useful in evaluating work of breathing and diaphragm atrophy, predicting successful weaning, and diagnosing critically ill patients. This technique has been used to determine reduced diaphragmatic function in patients with chronic obstructive pulmonary disease and interstitial diseases, while in those with COVID-19, diaphragmatic ultrasound has been used to predict weaning failure from mechanical ventilation.
\end{abstract}

Keywords: Diaphragm ultrasound, Bedside, Weaning, Interstitial lung disease, Chronic obstructive lung disease, COVID-19.

\begin{tabular}{|l|l|l|l|}
\hline Article History & Received: August 2, 2021 & Revised: October 11, 2021 & Accepted: November 11, 2021
\end{tabular}

\section{INTRODUCTION}

The diaphragm is a dome-shaped, fibromuscular respiratory muscle that separates the thorax from the abdomen. It is the most important respiratory muscle and is responsible for $75 \%$ of respiratory movements [1]. Diaphragmatic movement facilitates inspiratory and expiratory air flow for respiration, airway clearance, and speech [2], and diaphragmatic dysfunction (DD) may partly explain the symptoms of patients with respiratory diseases, such as dyspnea, decreased functional capacity, and respiratory failure. Causes of DD are varied; the principal etiologies are neurological, neuromuscular, and respiratory etiologies [3], and other causes are related to sepsis, cardiogenic shock, and hypercapnic respiratory failure [2]. DD has also been reported in $80 \%$ of patients on mechanical ventilation [4].

The gold standard for the evaluation of diaphragmatic function is transpulmonary pressure measurement after phrenic nerve stimulation [5]. Other methods include fluoroscopy, computed axial tomography, and magnetic resonance imaging [6]. Recently, the use of diaphragmatic ultrasound (DU) has increased due to its high availability, low associated costs, and safety, though its effectiveness depends on the collaboration of

\footnotetext{
* Address correspondence to this author at the Instituto Nacional del Tórax; Facultad de Medicina, Universidad de Chile. Jose Miguel Infante 717, Providencia, Santiago, Chile; Tel: +56-963726777;

E-mail: sebastianluxfebre@gmail.com
}

each patient. DU has been used to evaluate patients with interstitial lung disease, chronic obstructive pulmonary disease (COPD) [7], those weaning from mechanical ventilation [8], and most recently, patients with COVID-19 $[9,10]$.

\section{DIAPHRAGM ULTRASOUND}

DU is a useful tool for evaluating diaphragmatic movement, both statically and dynamically. Diaphragmatic thickness is a static measure obtained by measuring the distance between the two hyperechoic layers in the zone of apposition (ZOA). On the other hand, diaphragmatic thickening is a dynamic variable that represents the relationship between the difference in diaphragmatic thickness between two lung volumes divided by the thickness of the largest volume [11]. Another dynamic process is a diaphragmatic excursion, which can be determined through various methods: measurement of the downward movement of the left branch of the portal vein in the supine position while the patient is seated; measurement of the craniocaudal movement of the diaphragm in the supine position [12]; movement of the lung silhouette (curtain sign) in both hemidiaphragms with the patient seated; and measurement of the length of the diaphragm in the ZOA with residual volume and at total lung capacity, while the patient is seated [13]. 


\section{DIAPHRAGM ULTRASOUND IN INTENSIVE CARE UNITS}

Diaphragmatic weakness is one of the main complications of invasive mechanical ventilation (IMV). Comorbidities, acute pathology, drugs, and mechanical ventilation itself are factors that lead to this dysfunction [14], which produces weaning failure [15], prolonged mechanical ventilation [4], prolonged stays in intensive care units (ICU) [16], and increased mortality [2]. DU evaluates DD in four scenarios: diagnosis of dysfunction, evaluation of work of breathing (WOB), identification of atrophy, and prediction of IMV weaning outcome [17]. To diagnosis DD, the absence of neuromuscular relaxation associated with spontaneous mechanical ventilation is required [18]. Diaphragmatic paralysis is diagnosed by evaluating paradoxical movement or immobility of the hemidiaphragm during unassisted deep breathing. Diaphragmatic paresis is defined as the excursion of the hemidiaphragm less than $10 \mathrm{~mm}$ during deep unassisted breathing [19].

Valette et al. reported that the prevalence of DD in patients with acute respiratory failure at the time of admission to the ICU was $2.2 \%$; all patients had acute hypercapnic respiratory failure associated with alveolar hypoventilation [19]. Lu et al. found a $34 \%$ prevalence of DD among a cohort of patients with prolonged mechanical ventilation, which was defined as 3 or more unsuccessful spontaneous ventilation tests, or more than 7 days of ventilation after the first spontaneous ventilation test [20].

With respect to the evaluation of WOB, Umbrello et al. studied 25 patients who were ventilated in pressure support mode during the postoperative period following major surgeries. The authors compared diaphragmatic thickness and excursion versus the diaphragmatic and esophageal pressuretime product (indicators of WOB), and their results suggested that thickness evaluated by DU is a good indicator of changes in WOB compared to changes in pressure-time product [21]. Additionally, Vivier et al. evaluated 12 patients on noninvasive ventilation after weaning from IMV. The thickness and thickening fraction were compared with the diaphragmatic pressure-time product at three different levels of pressure support. Results showed that higher levels of support were associated with decreases in the pressure-time product and the thickening fraction; diaphragmatic thickening fraction is thus an alternative to non-invasively evaluate WOB [22].

DU can also evaluate atrophy and monitor expiratory diaphragmatic thickness. Zambon et al. prospectively followed 40 patients with IMV from their ICU admission until discharge. A $7.5 \%$ decrease in diaphragmatic thickness was observed in patients ventilated in controlled modalities, a 5.3\% decrease among those with high-support ventilation, and a $1.5 \%$ decrease in those with low-support ventilation; in contrast, a $2.3 \%$ increase in thickness was observed in patients with spontaneous ventilation [17]. Goligher et al. evaluated the clinical impact of diaphragmatic atrophy by daily evaluating diaphragmatic thickness in 211 patients in VMI. Thickness decreased in $10 \%$ of the patients analyzed, and this decrease was associated with a lower probability of weaning from mechanical ventilation, a prolonged stay in the ICU, and an increased risk of complications. Nevertheless, an increase in thickness was also associated with prolonged mechanical ventilation. Patients who presented a thickening fraction between 15 and $30 \%$ during the first 3 days of ventilation were associated with a shorter duration of IMV [14].

Thickening fraction has also been used as a predictor of weaning success. DiNino et al. prospectively followed 63 patients on spontaneous T-tube ventilation and pressure support and observed that a thickening fraction over $30 \%$ predicted successful weaning, with $88 \%$ of patients achieving spontaneous ventilation and $71 \%$ requiring only pressure support [23]. Different studies have corroborated the usefulness of the thickening fraction for predicting weaning, establishing cut-off values ranging from 20 to $34 \%$ [4, 24].

Another measure that has proven useful to predict weaning success is the diaphragmatic excursion. Kim et al. analyzed this parameter in 88 patients who required IMV for more than 48 hours under spontaneous ventilation test conditions, and established $10 \mathrm{~mm}$ as the excursion cut-off value for the prediction of weaning success [25]. Other authors have reported excursions between 9.5 to $14 \mathrm{~mm}$ as predictors of success $[15,26]$. Nevertheless, there is not yet sufficient evidence from clinical trials to support the superiority and routine use of one indicator, i.e., thickening fraction, or another, i.e., diaphragmatic excursion, in the weaning process.

\section{DIAPHRAGM ULTRASOUND IN CHRONIC OBSTRUCTIVE PULMONARY DISEASE}

COPD is characterized by persistent respiratory symptoms associated with chronic airflow limitation and parenchymal destruction [21]. Dynamic lung hyperinflation (DLH) plays a central role in the development of dyspnea and decreased functional capacity in EPOC, and it has two components: a static component, characterized by a decrease in lung elastance and destruction of the lung parenchyma, and a dynamic component which indicates the inability to eliminate all exhaled air before the next inspiration. Airflow limitation and DLH are the main causative factors of dyspnea in COPD patients.

DU and specific measurements, like diaphragmatic thickening and diaphragmatic excursion, can play a role in the evaluation of DD and can be correlated with pulmonary function tests, as evidenced by a number of studies. Baria et al. evaluated the diaphragmatic thickness and the thickening fraction in patients with COPD and compared them with a cohort of healthy people. There were no differences observed in diaphragmatic thickness or in the thickening fraction between the groups, except for the subgroup with severe air trapping [7]. For their part, Okura et al. evaluated diaphragmatic thickening at different volumes: total lung capacity, residual functional capacity, and residual volume in COPD and healthy patients. COPD patients showed a reduced diaphragmatic thickness in total lung capacity (TLC) though not functional residual capacity (FRC) or residual volume (RV) compared to healthy control. Furthermore, the thickening fraction was lower in COPD patients [27].

Other researchers have evaluated the relationship between diaphragmatic variables and exacerbations in patients with 
COPD. Lim et al. studied diaphragmatic thickening and diaphragmatic excursion in patients hospitalized due to a COPD exacerbation, from day 3 of their admission until 2 weeks post-discharge and found that diaphragmatic thickening decreases at the moment of exacerbation compared to the patients' follow-up ultrasound; however, diaphragmatic excursion did not change. The authors also showed a correlation between change in diaphragmatic excursion and the period of time before the next crisis [28]. Eryüksel et al. also evaluated the association between diaphragmatic thickening and the possibility of developing symptoms and exacerbations in a cohort of COPD patients by examining demographic, symptomatic, and functional variables, and they observed that diaphragmatic thickening is correlated with age, but not with sex, smoking, body mass index (BMI), exacerbations, or symptom scores [29]. In the same vein, Ogan et al. evaluated diaphragmatic thickening at tidal volume and at maximum inspiration in COPD patients and healthy subjects. There was no correlation found between these parameters and severity of COPD, respiratory function, the frequency of exacerbations or symptoms (mMRC) [30].

Ramachandran et al. evaluated diaphragmatic function in patients with moderate COPD by measuring diaphragmatic excursion, diaphragmatic thickening, and the length of the ZOA in TLC, FRC, and RV. They reported a lower diaphragmatic thickness compared to the control group and a small area of diaphragmatic apposition in patients with COPD in residual volume. There were no significant differences found in diaphragmatic excursion [13]. Shiraishi et al. also studied the correlation between maximum diaphragmatic excursion and ventilatory parameters in COPD patients and found that these patients had a reduced maximum diaphragmatic excursion compared to healthy subjects. They also demonstrated that diaphragmatic excursion is directly correlated with maximal oxygen consumption and with the change in inspiratory capacity in both COPD and healthy patients [31]. He et al. prospectively observed 137 patients, distributed in four groups, i.e., those with COPD, idiopathic pulmonary fibrosis (IPF), IPF with emphysema, and healthy controls, to evaluate diaphragmatic excursion. Their results showed that diaphragmatic mobility is in negative correlation with the degree of emphysema but does not correlate with the degree of fibrosis [32].

In summary, the variables evaluated through DU in COPD patients correlate with pulmonary function tests and can predict the risk of COPD exacerbation, though they do not correlate with symptoms or the severity of COPD.

\section{DIAPHRAGM ULTRASOUND IN INTERSTITIAL LUNG DISEASE}

Interstitial lung disease (ILD) is a heterogeneous group of conditions characterized by bilateral opacities that extensively compromise the pulmonary fields [33]. This group of diseases is associated with substantial morbidity and mortality [34] and impaired quality of life [35]. There is also growing evidence that respiratory muscle function is impaired [36, 37]. Several underlying pathophysiological mechanisms have been proposed: physical deconditioning, systemic pro-inflammatory states [38], hypoxia, malnutrition and sarcopenia, corticosteroid-induced myopathy [39], and muscle overload due to increased lung elastic recoil of the fibrotic lung [35, 40].

Over the last decade, lung ultrasonography has been reported as a complementary tool to diagnose ILD and followup with affected patients [41 - 44]. As mentioned above, He et al. found no differences in diaphragm excursion between patients with idiopathic pulmonary fibrosis and healthy controls [32]. Santana et al. evaluated diaphragmatic mobility in 40 patients with different types of ILD, who presented reduced diaphragmatic mobility during deep breathing and a lower thickening fraction compared to healthy controls. In addition, the authors were able to determine that diaphragmatic mobility correlates with the predicted forced vital capacity (FVC) and that the cutoff value of $60 \%$ predicted $\mathrm{FVC}$ is highly accurate for the diagnosis of DD [45]. These results were confirmed by Boccatonda et al., who compared diaphragmatic excursion in 12 IPF patients and 12 healthy subjects and found a significant reduction of mean diaphragmatic excursion in IPF patients, which was detectable in deep breathing maneuver only. Furthermore, there was a positive correlation observed between FVC and diaphragmatic mobility in subjects with IPF [46]. In another study, Santana et $a l$. evaluated diaphragmatic mobility and thickness during quiet and deep breathing and calculated thickening fraction in 30 subjects with IPF and 30 healthy controls. They observed similar diaphragmatic excursion in both groups in quiet breathing; patients with IPF had a greater diaphragmatic thickness but a lower thickening fraction than the healthy participants. Moreover, excursion and diaphragmatic thickening during deep breathing were positively correlated with lung function, exercise tolerance, and quality of life, but inversely correlated with dyspnea. Most of the fibrotic patients had lower thickening fraction, and they had greater dyspnea and exercise intolerance, lower quality of life and lung function [47].

\section{DIAPHRAGM ULTRASOUND IN COVID-19}

The use of DU in COVID-19 patients is a new and growing field of research. Corradi et al. prospectively studied 27 COVID-19 patients admitted to the ICU for continuous positive airway pressure (CPAP) before considering invasive ventilation. In these patients, diaphragmatic thickening was measured prior to connection to CPAP. They demonstrated that diaphragmatic thickening less than $21.4 \%$ predicts CPAP failure [9]. This group also retrospectively reviewed a cohort of 77 patients with COVID-19 admitted to the ICU and observed that a diaphragmatic thickness less than $2.2 \mathrm{~mm}$ at the end of expiration was associated with a higher probability of requiring IMV or death [10]. Lassola et al. prospectively observed 14 patients connected to IMV. They evaluated the correlation between esophageal pressure at three levels of pressure support and central venous pressure or thickening fraction. All these variables were measured at tidal volume, and there was a positive correlation between thickening fraction and esophageal pressure change [48]. In this context, the evaluation of diaphragmatic function in COVID-19 extends beyond what is known of DD in ICU, and DU is a simple, useful and inexpensive way to evaluate this function. 
Table 1. Diaphragmatic paralysis can be diagnosed by measuring diaphragmatic thickness and thickening in quiet and deep breathing, an easy and non-expensive diagnostic technique.

\begin{tabular}{|c|c|c|c|c|c|c|}
\hline Authors & Diseases & Thickness & Thickening Fraction & $\begin{array}{l}\text { Thickening Ratio } \\
\text { (Tmax/Tmin) }\end{array}$ & Excursion & ZOA \\
\hline Zambon et al., 2017 [17] & ICU - DD & N. E. & N.E. & N.E. & $<10 \mathrm{~mm}$ & N.E. \\
\hline Zambon et al., 2016 [51] & ICU - Atrophy & Yes & N.E. & N.E. & N. E. & N.E. \\
\hline $\begin{array}{c}\text { DiNino et al., } 2013 \\
{[23]}\end{array}$ & ICU - Weaning Outcome & Yes & $>30 \%$ & N.E. & N.E. & N.E. \\
\hline Jung et al., 2016 [52] & ICU - Weaning Outcome & Yes & $>20 \%$ & N.E. & N.E. & N.E. \\
\hline Farghaly et al., 2016 [24] & ICU - Weaning Outcome & Yes & $>34 \%$ & N. E. & N. E. & N. E. \\
\hline Kim et al., 2011 [25] & ICU - Weaning Outcome & N.E. & N.E. & N.E. & $>10 \mathrm{~mm}$ & N.E. \\
\hline Dres et al., 2017 [15] & ICU - Weaning Outcome & N.E. & N.E. & N.E. & $>9.5 \mathrm{~mm}$ & N.E. \\
\hline $\begin{array}{c}\text { Spadaro et al., } 2016 \\
{[26]}\end{array}$ & ICU - Weaning Outcome & N.E. & N.E. & N.E. & $>14 \mathrm{~mm}$ & N.E. \\
\hline Baria et al., 2014 [7] & COPD & No & N.E. & $\begin{array}{l}\text { Yes, in severe air } \\
\text { trapping. }\end{array}$ & N.E. & N.E. \\
\hline Eryüksen et al., 2017 [29] & COPD & N. E. & No. & N. E. & N.E. & N.E. \\
\hline Lim et al., 2019 [28] & COPD & N.E. & Yes & N.E. & No & N.E. \\
\hline Ogan et al., 2019 [30] & COPD & No & N.E. & N.E. & N.E. & N.E. \\
\hline Okura et al., 2020 [27] & COPD & Yes (TdiTLC). & N. E. & Yes. & N.E. & N.E. \\
\hline Ramachandran et al., 2020 [13] & COPD & Yes & N.E. & N.E. & No & Yes (RV) \\
\hline Shiraishi et al., 2020 [31] & COPD & N. E. & N. E. & N.E. & Yes & N.E. \\
\hline He et al., 2014 [32] & COPD & N.E. & N. E. & N.E. & Yes (TLC) & N.E. \\
\hline He et al., 2014 [32] & ILD & N.E. & N.E. & N.E. & Yes (TLC) & N.E. \\
\hline $\begin{array}{c}\text { Santana et al., } 2016 \\
{[45]}\end{array}$ & ILD & Yes. & Yes. & N.E. & Yes (DB) & N.E. \\
\hline Boccatonda et al., 2018 [46] & ILD & N. E. & N.E. & N.E. & Yes (DB) & N.E. \\
\hline $\begin{array}{c}\text { Santana et al., } 2019 \\
{[47]}\end{array}$ & ILD & Yes & Yes & N. E. & Yes (DB) & N.E. \\
\hline Corradi et al., $2020[10]$ & COVID-19 & N.E. & $\begin{array}{c}\text { Failure } \\
<21.4 \%\end{array}$ & N.E. & N.E. & N.E. \\
\hline $\begin{array}{c}\text { Corradi et al., } 2021 \\
{[9]}\end{array}$ & COVID-19 & Yes & N.E. & N.E. & N.E. & N.E. \\
\hline Lassola et al., 2021 [48] & COVID-19 & N.E. & Yes & N.E. & N.E. & N.E. \\
\hline
\end{tabular}

ICU: Intensive care unit, DD: Diaphragmatic dysfunction, COPD: Chronic obstructive pulmonary disease, ILD: Interstitial lung disease, N.E.: Not evaluated, TLC: Total lung capacity, RV: Residual volume, DB: Deep breathing, TdiTLC: diaphragmatic thickening at TLC.

\section{DIAPHRAGMATIC PARALYSIS}

Diaphragmatic paralysis is typically suspected in dyspneic patients with an elevated hemidiaphragm in a chest $\mathrm{x}$-ray. The selection of confirmatory test depends on their availability and invasiveness. The DU is used as a diagnostic tool in diaphragmatic paralysis. Gottersman et al. evaluated patients with suspected diaphragmatic paralysis and found that among patients with unilateral paralysis, diaphragmatic thickness and thickening were significantly less than in healthy controls [49]. In the same vein, Boussuges et al. evaluated paralyzed diaphragm by M-mode ultrasonography, and the absence of movement and paradoxical movement was associated with paralyzed diaphragm during quiet and deep breathing [12]. Caleffi-Pereira et al. also studied diaphragmatic paralysis in 27 patients with unexplained dyspnea and demonstrated that mobility during quiet and deep breathing was reduced in these patients compared with their healthy counterparts; these authors also showed that thickness at functional capacity and total lung capacity was reduced in paralyzed hemidiaphragm [50]. Thus, diaphragmatic paralysis can be diagnosed by measuring diaphragmatic thickness and thickening in quiet and deep breathing, an easy and non-expensive diagnostic technique [51, 52] (Table 1).

\section{CONCLUSION}

Although DU is a tool still under development, its versatility and ability to give us information in dynamic situations suggest that its use will increase significantly in the coming years. In a critical care setting, where patients are usually too sick to carry out other tests (i.e., computed tomography), DU is invaluable as a bedside tool. Measurement of the static and dynamic variables is standardized, but it remains to be determined which of all possible measurements is best while conducting an ultrasonography evaluation. Most reports are focused on weaning from mechanical ventilation and adding information about diaphragmatic dysfunction, as summarized in this review. In COPD, several ultrasound parameters have been evaluated. It appears that measurements up to total lung capacity increase the sensitivity of the test. Regarding diaphragmatic excursion, lately, there have been positive results when measuring maximum inspiration. The measurement of diaphragmatic length in the $\mathrm{ZOA}$ is a 
promising variable when assessing diaphragmatic function in a patient breathing in tidal volume. In ILD, the diaphragmatic excursion is diminished and correlates with the FVC. Even more, thickening fraction is correlated with lung function, exercise tolerance, and quality of life. The usefulness of DU in COVID-19 is focused on patients in the ICU. While the utility of DU in patients with COVID-19 sequelae has yet to be fully evaluated, it is an easy way to diagnose diaphragmatic paralysis.

\section{CONSENT FOR PUBLICATION}

Not applicable.

\section{FUNDING}

None.

\section{CONFLICT OF INTEREST}

The authors declare no conflict of interest, financial or otherwise.

\section{ACKNOWLEDGEMENTS}

Declared none.

\section{REFERENCES}

[1] Donaldson AV, Maddocks M, Martolini D, Polkey MI, Man WD-C. Muscle function in COPD: A complex interplay. Int J Chron Obstruct Pulmon Dis 2012; 7: 523-35. [PMID: 22973093]

[2] Dres M, Goligher EC, Heunks LMA, Brochard LJ. Critical illnessassociated diaphragm weakness. Intensive Care Med 2017; 43(10): 1441-52.

[http://dx.doi.org/10.1007/s00134-017-4928-4] [PMID: 28917004]

[3] McCool FD, Tzelepis GE. Dysfunction of the diaphragm. N Engl J Med 2012; 366(10): 932-42.

[http://dx.doi.org/10.1056/NEJMra1007236] [PMID: 22397655]

[4] Jung B, Moury PH, Mahul M, et al. Diaphragmatic dysfunction in patients with ICU-acquired weakness and its impact on extubation failure. Intensive Care Med 2016; 42(5): 853-61. [http://dx.doi.org/10.1007/s00134-015-4125-2] [PMID: 26572511]

[5] Bolton CF, Grand'Maison F, Parkes A, Shkrum M. Needle electromyography of the diaphragm. Muscle Nerve 1992; 15(6): 678-81.

[http://dx.doi.org/10.1002/mus.880150608] [PMID: 1508232]

[6] Dubé B-P, Dres M. Diaphragm dysfunction: Diagnostic approaches and management strategies. J Clin Med 2016; 5(12)E113 [http://dx.doi.org/10.3390/jcm5120113] [PMID: 27929389]

[7] Baria MR, Shahgholi L, Sorenson EJ, et al. B-mode ultrasound assessment of diaphragm structure and function in patients with COPD. Chest 2014; 146(3): 680-5.

[http://dx.doi.org/10.1378/chest.13-2306] [PMID: 24700122]

[8] Dres M, Goligher EC, Dubé B-P, et al. Diaphragm function and weaning from mechanical ventilation: An ultrasound and phrenic nerve stimulation clinical study. Ann Intensive Care 2018; 8(1): 53. [http://dx.doi.org/10.1186/s13613-018-0401-y] [PMID: 29687276]

[9] UCARE (Ultrasound in Critical care and Anesthesia Research Group), Corradi F, Isirdi A, Malacarne P, Santori G, Barbieri G, Low diaphragm muscle mass predicts adverse outcome in patients hospitalized for COVID-19 pneumonia: an exploratory pilot study. Minerva Anestesiol [Internet] 2021; 87(4) Available from: https://www.minervamedica.it/index2.php?show=R02Y2021N04A043 2

[10] Corradi F, Vetrugno L, Orso D, et al. Diaphragmatic thickening fraction as a potential predictor of response to continuous positive airway pressure ventilation in COVID-19 pneumonia: A single-center pilot study. Respir Physiol Neurobiol 2021; 284103585 [http://dx.doi.org/10.1016/j.resp.2020.103585] [PMID: 33197604]

[11] Matamis D, Soilemezi E, Tsagourias M, et al. Sonographic evaluation of the diaphragm in critically ill patients. Technique and clinical applications. Intensive Care Med 2013; 39(5): 801-10. [http://dx.doi.org/10.1007/s00134-013-2823-1] [PMID: 23344830]

[12] Boussuges A, Gole Y, Blanc P. Diaphragmatic motion studied by mmode ultrasonography: Methods, reproducibility, and normal values. Chest 2009; 135(2): 391-400.

[http://dx.doi.org/10.1378/chest.08-1541] [PMID: 19017880]

[13] Ramachandran P, Devaraj U, Patrick B, et al. Ultrasonographic assessment of skeletal muscle mass and diaphragm function in patient with chronic obstructive pulmonary disease: A case-control study. Lung India 2020; 37(3): 220-6.

[http://dx.doi.org/10.4103/lungindia.lungindia_103_19] [PMID: 32367843]

[14] Goligher EC, Dres M, Fan E, et al. Mechanical ventilation-induced diaphragm atrophy strongly impacts clinical outcomes. Am J Respir Crit Care Med 2018; 197(2): 204-13.

[http://dx.doi.org/10.1164/rccm.201703-0536OC] [PMID: 28930478]

[15] Dres M, Dubé B-P, Mayaux J, et al. Coexistence and impact of limb muscle and diaphragm weakness at time of liberation from mechanical ventilation in medical intensive care unit patients. Am J Respir Crit Care Med 2017; 195(1): 57-66.

[http://dx.doi.org/10.1164/rccm.201602-0367OC] [PMID: 27310484]

[16] Demoule A, Molinari N, Jung B, et al. Patterns of diaphragm function in critically ill patients receiving prolonged mechanical ventilation: A prospective longitudinal study. Ann Intensive Care 2016; 6(1): 75. [http://dx.doi.org/10.1186/s13613-016-0179-8] [PMID: 27492005]

[17] Zambon M, Greco M, Bocchino S, Cabrini L, Beccaria PF, Zangrillo A. Assessment of diaphragmatic dysfunction in the critically ill patient with ultrasound: A systematic review. Intensive Care Med 2017; 43(1): 29-38.

[http://dx.doi.org/10.1007/s00134-016-4524-z] [PMID: 27620292]

[18] Santana PV, Cardenas LZ, de Albuquerque ALP, de Carvalho CRR, Caruso P. Diaphragmatic ultrasound: A review of its methodological aspects and clinical uses. J bras pneumol 46 Available from: http://www.scielo.br/j/jbpneu/a/99jsWtTCzQhdJmKRN7qdbHR/?lang $=\mathrm{en}$

[19] Valette X, Seguin A, Daubin C, et al. Diaphragmatic dysfunction at admission in intensive care unit: The value of diaphragmatic ultrasonography. Intensive Care Med 2015; 41(3): 557-9. [http://dx.doi.org/10.1007/s00134-014-3636-6] [PMID: 25600191]

[20] Lu Z, Xu Q, Yuan Y, Zhang G, Guo F, Ge H. Diaphragmatic dysfunction is characterized by increased duration of mechanical ventilation in subjects with prolonged weaning. Respir Care 2016; 61(10): 1316-22.

[http://dx.doi.org/10.4187/respcare.04746] [PMID: 27682813]

[21] Umbrello M, Formenti P, Longhi D, et al. Diaphragm ultrasound as indicator of respiratory effort in critically ill patients undergoing assisted mechanical ventilation: A pilot clinical study. Crit Care 2015; 19(1): 161 .

[http://dx.doi.org/10.1186/s13054-015-0894-9] [PMID: 25886857]

[22] Vivier E, Mekontso Dessap A, Dimassi S, et al. Diaphragm ultrasonography to estimate the work of breathing during non-invasive ventilation. Intensive Care Med 2012; 38(5): 796-803.

[http://dx.doi.org/10.1007/s00134-012-2547-7] [PMID: 22476448]

[23] DiNino E, Gartman EJ, Sethi JM, McCool FD. Diaphragm ultrasound as a predictor of successful extubation from mechanical ventilation. Thorax 2014; 69(5): 423-7.

[http://dx.doi.org/10.1136/thoraxjnl-2013-204111] [PMID: 24365607]

[24] Farghaly S, Hasan AA. Diaphragm ultrasound as a new method to predict extubation outcome in mechanically ventilated patients. Aust Crit Care 2017; 30(1): 37-43.

[http://dx.doi.org/10.1016/j.aucc.2016.03.004] [PMID: 27112953]

[25] Kim WY, Suh HJ, Hong S-B, Koh Y, Lim C-M. Diaphragm dysfunction assessed by ultrasonography: Influence on weaning from mechanical ventilation. Crit Care Med 2011; 39(12): 2627-30. [http://dx.doi.org/10.1097/CCM.0b013e3182266408] [PMID: 21705883]

[26] Spadaro S, Grasso S, Mauri T, et al. Can diaphragmatic ultrasonography performed during the T-tube trial predict weaning failure? The role of diaphragmatic rapid shallow breathing index. Crit Care 2016; 20(1): 305.

[http://dx.doi.org/10.1186/s13054-016-1479-y] [PMID: 27677861]

[27] Okura K, Iwakura M, Shibata K, et al. Diaphragm thickening assessed by ultrasonography is lower than healthy adults in patients with chronic obstructive pulmonary disease. Clin Respir J 2020; 14(6): 521-6.

[http://dx.doi.org/10.1111/crj.13161] [PMID: 32043736]

[28] Lim SY, Lim G, Lee YJ, et al. Ultrasound assessment of 
diaphragmatic function during acute exacerbation of chronic obstructive pulmonary disease: A pilot study. Int J Chron Obstruct Pulmon Dis 2019; 14: 2479-84.

[http://dx.doi.org/10.2147/COPD.S214716] [PMID: 31806957]

[29] Eryüksel E, Cimşit C, Bekir M, Cimsit Ç, Karakurt S. Diaphragmatic thickness fraction in subjects at high-risk for COPD exacerbations. Respir Care 2017; 62(12): 1565-70.

[http://dx.doi.org/10.4187/respcare.05646] [PMID: 28874613]

[30] Ogan N, Aydemir Y, EVrin T, et al. Diaphragmatic thickness in chronic obstructive lung disease and relationship with clinical severity parameters. Turk J Med Sci 2019; 49(4): 1073-8.

[http://dx.doi.org/10.3906/sag-1901-164] [PMID: 31293145]

[31] Shiraishi M, Higashimoto Y, Sugiya R, et al. Diaphragmatic excursion correlates with exercise capacity and dynamic hyperinflation in COPD patients. ERJ Open Res 2020; 6(4): 00589-2020. [http://dx.doi.org/10.1183/23120541.00589-2020] [PMID: 33447614]

[32] He L, Zhang W, Zhang J, et al. Diaphragmatic motion studied by Mmode ultrasonography in combined pulmonary fibrosis and emphysema. Lung 2014; 192(4): 553-61.

[http://dx.doi.org/10.1007/s00408-014-9594-5] [PMID: 24818955]

[33] Travis WD, Costabel U, Hansell DM, et al. An official American Thoracic Society/European Respiratory Society statement: Update of the international multidisciplinary classification of the idiopathic interstitial pneumonias. Am J Respir Crit Care Med 2013; 188(6): 733-48.

[http://dx.doi.org/10.1164/rccm.201308-1483ST] [PMID: 24032382]

[34] Antoniou KM, Margaritopoulos GA, Tomassetti S, Bonella F, Costabel U, Poletti V. Interstitial lung disease. Eur Respir Rev 2014; 23(131): 40-54

[http://dx.doi.org/10.1183/09059180.00009113] [PMID: 24591661]

[35] Raghu G, Collard HR, Egan JJ, et al. An official ATS/ERS/JRS/ALAT statement: idiopathic pulmonary fibrosis: Evidence-based guidelines for diagnosis and management. Am J Respir Crit Care Med 2011; 183(6): 788-824.

[http://dx.doi.org/10.1164/rccm.2009-040GL] [PMID: 21471066]

[36] Holland AE. Exercise limitation in interstitial lung disease mechanisms, significance and therapeutic options. Chron Respir Dis 2010; 7(2): 101-11.

[http://dx.doi.org/10.1177/1479972309354689] [PMID: 20056733]

[37] Walterspacher S, Schlager D, Walker DJ, Müller-Quernheim J, Windisch W, Kabitz H-J. Respiratory muscle function in interstitial lung disease. Eur Respir J 2013; 42(1): 211-9.

[http://dx.doi.org/10.1183/09031936.00109512] [PMID: 23258788]

[38] Prasse A, Müller-Quernheim J. Non-invasive biomarkers in pulmonary fibrosis. Respirology 2009; 14(6): 788-95.

[http://dx.doi.org/10.1111/j.1440-1843.2009.01600.x] [PMID: 19703061]

[39] Dekhuijzen PN, Decramer M. Steroid-induced myopathy and its significance to respiratory disease: A known disease rediscovered. Eur Respir J 1992; 5(8): 997-1003 [PMID: 1426209]

[40] Javaheri S, Sicilian L. Lung function, breathing pattern, and gas exchange in interstitial lung disease 1992; 47(2): 93-7. [http://dx.doi.org/10.1136/thx.47.2.93]
[41] Lo Giudice V, Bruni A, Corcioni E, Corcioni B. Ultrasound in the evaluation of interstitial pneumonia. J Ultrasound 2008; 11(1): 30-8. [http://dx.doi.org/10.1016/j.jus.2007.10.002] [PMID: 23396220]

[42] Sperandeo M, Filabozzi P, Varriale A, et al. Role of thoracic ultrasound in the assessment of pleural and pulmonary diseases. J Ultrasound 2008; 11(2): 39-46. [http://dx.doi.org/10.1016/j.jus.2008.02.001] [PMID: 23396553]

[43] Wang Y, Gargani L, Barskova T, Furst DE, Cerinic MM. Usefulness of lung ultrasound B-lines in connective tissue disease-associated interstitial lung disease: A literature review. Arthritis Res Ther 2017; 19(1): 206.

[http://dx.doi.org/10.1186/s13075-017-1409-7] [PMID: 28923086]

[44] Gagnon P, Guenette JA, Langer D, et al. Pathogenesis of hyperinflation in chronic obstructive pulmonary disease. Int J Chron Obstruct Pulmon Dis 2014; 9: 187-201. [PMID: 24600216]

[45] Santana PV, Prina E, Albuquerque ALP, Carvalho CRR, Caruso P. Identifying decreased diaphragmatic mobility and diaphragm thickening in interstitial lung disease: The utility of ultrasound imaging. J Bras Pneumol 2016; 42(2): 88-94.

[http://dx.doi.org/10.1590/S1806-37562015000000266] [PMID: 27167428]

[46] Boccatonda A, Decorato V, Cocco G, Marinari S, Schiavone C Ultrasound evaluation of diaphragmatic mobility in patients with idiopathic lung fibrosis: A pilot study. Multidiscip Respir Med 2018; 14(1): 1 .

[http://dx.doi.org/10.1186/s40248-018-0159-y] [PMID: 30651988]

[47] Santana PV, Cardenas LZ, de Albuquerque ALP, de Carvalho CRR, Caruso P. Diaphragmatic ultrasound findings correlate with dyspnea, exercise tolerance, health-related quality of life and lung function in patients with fibrotic interstitial lung disease. BMC Pulm Med 2019; 19(1): 183.

[http://dx.doi.org/10.1186/s12890-019-0936-1] [PMID: 31638951]

[48] Lassola S, Miori S, Sanna A, Cucino A, Magnoni S, Umbrello M. Central venous pressure swing outperforms diaphragm ultrasound as a measure of inspiratory effort during pressure support ventilation in COVID-19 patients. J Clin Monit Comput 2021

[http://dx.doi.org/10.1007/s10877-021-00674-4] [PMID: 33635495]

[49] Gottesman E, McCool FD. Ultrasound evaluation of the paralyzed diaphragm. Am J Respir Crit Care Med 1997; 155(5): 1570-4.

[http://dx.doi.org/10.1164/ajrccm.155.5.9154859] [PMID: 9154859]

[50] Caleffi-Pereira M, Pletsch-Assunção R, Cardenas LZ, et al. Unilateral diaphragm paralysis: A dysfunction restricted not just to one hemidiaphragm. BMC Pulm Med 2018; 18(1): 126 [http://dx.doi.org/10.1186/s12890-018-0698-1] [PMID: 30068327]

[51] Zambon M, Beccaria P, Matsuno J, et al. Mechanical ventilation and diaphragmatic atrophy in critically ill patients: An ultrasound study. Crit Care Med 2016; 44(7): 1347-52.

[http://dx.doi.org/10.1097/CCM.0000000000001657] [PMID: 26992064]

[52] Jung B, Moury PH, Mahul M, et al. Diaphragmatic dysfunction in patients with ICU-acquired weakness and its impact on extubation failure. Intensive Care Med 2016; 42(5): 853-61. [http://dx.doi.org/10.1007/s00134-015-4125-2] [PMID: 26572511]

\section{(c) 2021 Lux et al.}

This is an open access article distributed under the terms of the Creative Commons Attribution 4.0 International Public License (CC-BY 4.0), a copy of which is available at: https://creativecommons.org/licenses/by/4.0/legalcode. This license permits unrestricted use, distribution, and reproduction in any medium, provided the original author and source are credited. 